\title{
A cidade sob a póetica do artista: um estudo dos processos comunicativos na obra do artista plástico Moacir Andrade
}

THE CITY UNDER THE POETICS OF ARTIST: A STUDY OF COMMUNICATIVE PROCESSES IN THE WORK OF THE

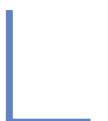
VISUAL ARTIST MOACIR ANDRADE

\section{Valter Frank Mesquita Lopes}

Professor do Departamento de Artes da Universidade Federal do Amazonas.

E-mail: valtermesquita@hotmail.com

\section{Sérgio Ivan Gil Braga}

Professor do Departamento de Antropologia da Universidade Federal do Amazonas.

E-mail: sigbraga@ufam.edu.br

Recebido em 28 de fevereiro de 2016. Aprovado em 14 de junho de 2016.

\section{Resumo}

Este artigo discute os processos comunicativos existentes nos desenhos do artista amazonense Moacir Andrade, buscando responder de que maneira esses processos se organizam no espaço semiótico composto pela obra do artista e pelo urbano na cidade de Manaus, tomando como corpus os seus desenhos das décadas de 1960 e 1970. Fundamentamos com os conceitos de semiose de Peirce e semiosfera de Lotman. Metodologicamente, partimos das categorias de análise propostas por Mesquita, compostas pelos sistemas de base, intermediários e de superfície.

Palavras-chave: Processos Comunicativos. Artes Plásticas. Urbano.

\section{Abstract}

This article discusses the existing communication processes in the drawings of the Amazonian artist Moacir Andrade, seeking to answer how these processes are organized in the semiotic space composed by the work of the artist and the urban in the city of Manaus, taking as corpus their designs of the 1960s and 1970s. We took as basis Peirce's semiosis and Lotman's semiosphere. Methodologically, we started from the analysis categories proposed by Mesquita, consisting of the basic systems, the intermediate and the surface ones.

Keywords: Communicative Processes. Visual Arts. Urban. 


\section{Introdução}

Este trabalho objetivou propor uma discussão sobre os processos comunicativos da obra do artista plástico amazonense Moacir Andrade e sua representação da cidade de Manaus, buscando compreender os diversos níveis de relações estabelecidas entre a obra do artista e a cidade. Para isso, partimos do cenário da cidade de Manaus na década de 1960, esquadrinhado por José Aldemir de Oliveira (2003) e do conceito de urbano de Louis Wirth (1967).

Moacir Andrade (1927-2016) realizou diversos desenhos desde a década de 1930, sendo o período de 1960 e 1970 o de maior produção em desenho do artista - momento este em que Manaus passava por mudanças em seu espaço urbano: a extinção da cidade flutuante em 1965, o advento da Zona Franca de Manaus em 1967, as políticas de incentivo à expansão de moradias, tendo como consequência a expansão territorial - período de efervecência cultural, promovido principalmente com a criação do Clube da Madrugada na década anterior e da Pinacoteca do Estado em 1964, pelo então governador Arthur Reis. No entanto, Moacir Andrade, que nasceu no dia 17 de março de 1927, na cidade de Manaus, cresceu em uma época em que se seguiu um insignificante crescimento da cidade, propiciado principalmente pela crise da borracha.

É a partir a década de 1940 que o artista inicia sua carreira na arte, sendo que na década de 1950 o artista toma projeção nacional, com sua primeira exposição em 1958, em Brasília, e internacional, em 1968, quando fez sua primeira viagem para fora do país, com exposições nos EUA e na França. Moacir Andrade desvenvolveu sua prática artística em meio a um cenário propício. O advento do Clube da Madrugada em 1954, no qual o próprio artista foi membro e pertencente ao primeiro núcleo (PÁSCOA, 2011), o que incitou no artista a busca por uma linguagem livre de convenções.

Com a criação da Pinacoteca do Estado do Amazonas, os artistas amazonenses ganharam um espaço onde puderam ver suas obras expostas permanentemente. Teve como primeiro diretor o próprio Moacir Andrade, que ficou no cargo por quatro anos. A Pinacoteca era, também, um espaço de formação artística, no qual funcionavam cursos de desenho e pintura, ministrados por Moacir Andrade, Álvaro Páscoa e Manoel Borges.

Sua obra se caracteriza por possuir várias fases criativas. Os primeiros trabalhos apresentam um cunho expressionista, talvez pela influência da obra de Portinari, produzindo algumas poucas obras com referência cubista, outras com o impressionismo, e outras ainda, abstratas. Pintou também paisagens, mas o que marcará sua obra é a produção pós-criação do Clube da Madrugada, quando o artista buscou se livrar de todo e qualquer 
indício acadêmico, construindo um esitlo próprio, de cunho fantástico, talvez fruto da representação do imaginário amazônico do pintor.

Para fins de análise, tomamos como corpus os desenhos de Moacir Andrade das décadas de 1960 e 1970, nos quais retrata o cotidiando e as cenas da organização da vida na cidade de Manaus no século 20, além de sua arquitetura, período em que tivemos mudanças substanciais na paisagem urbana. Analisamos 50 desenhos das décadas de 1960 e 1970 sob a luz dos conceitos de semiose de Peirce (1994), semiosfera de Lotman (1996) e das categorias propostas por Mesquita (2016). São elas: os sistemas de base, os sistemas intermediários e os sistemas de superfície.

Estruturamos este ensaio em duas partes. Na primeira, apresentamos os conceitos de urbano como modos de vida, de semiose e semiosfera, além das categorias de análises. Na segunda parte, analisamos na obra de Moacir Andrade as características dos sistemas de base, intermediários e de superfície e sua relação com o urbano na cidade de Manaus, com o intuito de compreender os processos comunicativos existentes entre a arte e a cidade.

O universo temático da obra de Moacir Andrade circula em torno da cultura popular, dos hábitos, costumes e modos de vida do povo amazonense, além da arquitetura da cidade (ANDRADE, 1974). Sobre isso, o artista lembra que "os personagens e lendas dos meus quadros têm a ver com a minha vida no interior de Manacapuru. Sou profundamente ligado às minhas origens. Ler eu leio tudo, mas escrever só escrevo e pinto sobre a Amazônia" (SOUZA, 2010, p. 96).

O artista caminhava pelas ruas da cidade; é possível perceber que ele andava muito pela cidade, observando os hábitos dos homens e a paisagem urbana. A figura do homem na cidade de Manaus é presente quase sempre em sua produção, e é representado a partir de pontos de vista peculiares. Geralmente, o pintor ia de canoa até a frente do rio para retratar os beiradões, os ribeirinhos, as palafitas às margens dos igarapés, ou caminhava pelas ruas e pontes observando. $\mathrm{O}$ artista nos relata que

gostava muito de andar pelos bairros de Manaus; desenvolvi muitos desenhos e telas, inspirados em São Raimundo e Educandos, bairros que ficam à margem do rio Negro. Retratei igrejas, o Porto Flutuante, o Mercado Adolpho Lisboa. Às vezes, sob o ponto de vista do rio, quando de uma canoa ficava horas pintando. Às vezes sob o ponto de vista da cidade, quando me posicionava em determinado local, desenhava ou pintava o que via no rio. Retratei belas construções do auge da borracha, as grades que formavam artísticos desenhos muitas roubadas ao longo tempo, os detalhes dos belos monumentos das praças. Saía retratando tudo em Manaus. Era incansável. (SOUZA, 2010, p. 105-106). 
Moacir Andrade não só é um artista que caminha pela cidade, consumindo-a como poética, mas também um pesquisador, que a estuda, estuda seus homens e seu modo de vida. Publicou mais de vinte livros, a maioria sobre os hábitos e costumes na cidade, pois a cidade atrai o artista.

\section{Base conceitutal para uma discusão dos processos comunicativos}

Como a cidade de Manaus se torna a principal temática nos desenhos de Moacir Andrade, compreender que ela não é um mero espaço depositário de pessoas ocupando lugares, mas um espaço vivo e dinâmico de manifestações da vida urbana, a ideia de urbano nos ajuda a entender o lugar de destaque da cidade no plano poético do artista. Para entender o conceito de urbano como modo de vida dos indivíduos na cidade, e tomando a ideia de que ela exerce uma enorme influência sobre o modo de vida das pessoas, Louis Wirth (1967) diz que

A urbanização já não denota meramente o processo pelo qual as pessoas são atraídas a uma localidade intitulada cidade e incorporadas em seu sistema de vida. Ela se refere também àquela acentuação cumulativa das características que distinguem o modo de vida associado com o crescimento das cidades e, finalmente, com as mudanças de sentido dos modos de vida reconhecidos como urbanos. (WIRTH, 1967, p. 101)

$\mathrm{O}$ autor entende o urbanismo como modo de vida. São esses modos de vida que a arte irá retratar sob o olhar do artista, imerso na realidade de seu tempo, em uma dinâmica que se percebe em atividade nas décadas de 1960 e 1970, na cidade de Manaus.

A relação que o artista plástico Moacir Andrade tem com a cidade parte da ideia de compreendê-la como manifestação do urbano. Entender o urbano como algo que estrapola a própria noção de cidade nos ajuda a ver a obra do artista como resultado de uma série de experiências com ela. Compreendemos o conceito de urbano como caracterizado pelos modos de vida de uma cidade a partir de Louis Wirth (1967). Para Wirth, esse conceito está ligado a características complexas que formam o modo de vida típico das cidades. Para Monte-Mór (2006), o urbano se apresenta como um adjetivo que diz respeito a um conjunto de relaçõs culturais, socioeconômicas e espaciais. Entender que a cidade é um todo complexo de relações, e que o artista está inserido nessa dinâmica, nos permite pensar o urbano como um espaço constituído pelos aspectos sociais, econômicos e culturais característicos de uma cidade. O urbano, então, compreende a cultura. José Aldemir de Oliveira (2000) concebe a cidade além da paisagem aparente. $\mathrm{O}$ autor diz que a cidade "se produz e reproduz a partir do cotidiano 
de quem a constrói, contendo vida, fragmentos de vida e a dimensão do uso do espaço e do tempo" (OLIVEIRA, 2000, p. 20). Oliveira se refere à memória como não estando no espaço construído, mas naqueles que a constroem. Essas características do modo de vida, do pensar e do agir, característico do urbano, fazem-nos crer na possibilidade de estudar esse urbano por meio das representações daqueles que "constroem" a cidade.

Assim, o urbano marca a esfera da vida cotidiana, indica de que modo se dão as relações na sociedade entre os seus vários construtores, como assinalou Oliveira, pois os modos de vida, as relações em sociedade, os elementos que marcam o social, o econômico, o político e o cultural, encontram-se em diálogos, e estes com a arte. Assim, o urbano se traduz em conteúdo expressivo na cultura da cidade. As atitudes, os hábitos, os tipos sociais, que é abarcada pela noção de cultura, fazem parte do urbano.

Como nosso olhar recai sobre os processos comunicativos existentes na obra do artista plástico Moacir Andrade, entender essas relações como parte de um todo complexo, cuja obra se encontra imersa, faz-nos perceber que não há como estudar a obra do artista sem levar em consideração o espaço cultural em que tanto a obra como o artista se inserem, no caso o urbano, podendo nosso estudo estar fadado ao erro.

Para compreender essa complexidade da arte que trata da cultura amazônica, partiremos dos conceitos de semiose, de Charles Sanders Peirce (1994), do conceito de semiosfera, de Iuri Lotman (1996), e das categorias de análise de Valter Mesquita (2016).

\section{Semiose e semiosfera}

Em Peirce, encontramos que todo processo de representação é um processo semiótico, e que a semiose é a cadeia de relações estabelecida pelo signo. Semiose é um conceito abstrato e geral da semiótica de Charles Sanders Peirce, visto que a semiótica é a doutrina da natureza essencial e variedades fundamentais da semiose possível (CP $5.488)^{1}$. Peirce apresenta seu conceito de semiose como sendo a ação entre o signo, o objeto a que o signo representa e o efeito que este pode causar em uma mente, gerando um interpretante (CP 2.92). O autor define o conceito de semiose como sendo

Toda a ação dinâmica, ou ação de força bruta, física ou psíquica, ou ocorre entre dois indivíduos (se reagem igualmente um sobre o outro, ou é um agente e outro paciente, total ou parcialmente) ou de qualquer forma é uma resultante de tais ações entre pares. Mas por "semiose" quero dizer, ao contrário, uma ação ou influência, que é, ou envolve, uma cooperação dos três termos, como um signo, seu objeto e seu interpretante, esta influência tri-relativa não sendo de forma alguma resolvido em ações entre pares. (CP 5.484, tradução nossa).

1 Doravante, o autor será citado como CP [número do volume].[número do parágrafo], para facilitar a referência. 
A semiose é um processo que envolve uma cooperação entre três signos, o que nos possibilita falar sobre relação e interação entre esses signos em processos de comunicação. Assim, entendemos o conceito de comunicação como sendo um processo relacional que envolve diversas linguagens em interação semiótica. O conceito de semiose de Peirce permite compreender a ação que os processos de geração de linguagem desencadeada por esses sistemas possibilitam. Pode-se entender a semiose sob o ponto de vista da comunicação "como lugar de produção de mensagem, isto é, de transformação da informação em signo; de geração e circulação de sentido; de construção de campos de significação; de criação de circuitos de respondibilidade" (MACHADO, 2003, p. 282). Semiose é compreendida como atividade de relação dialógica entre os códigos e linguagens, pois toda linguagem é um sistema formado por signos e todo signo implica em uma ação inteligente que envolve processos relacionais de representação.

Irene Machado chega a definir a semiose como comunicação ao valorizar a dinâmica dialógica nos processos de linguagem, ao passo que novas linguagens são criadas a partir do encontro de duas linguagens diferentes. A ideia de semiose enquanto comunicação permite entender os processos comunicativos na obra do artista Moacir Andrade com a cidade, conformando um espaço semiótico da cultura.

A ideia de espaço semiótico parte da fundamentação do conceito de semiosfera de Lotman (1996). Lotman diz poder pensar a cultura como um organismo vivo, espaço aberto à criação dos mais variados sistemas de signos. Essa ideia parte da concepção de que a cultura é a conjunção de diversos sistemas. Nesses termos, Lotman (2010) frisa que "é importante destacar o princípio de acordo com a qual a cultura é informação" (LOTMAN, 2010, p. 32).

A cultura se apresenta como constituída de sistemas de signos, estabelecendo uma dinâmica semiótica que possibilita tratar a cultura como processo semiótico que não pode ser considerado isolado (IVÁNOV et al., 2003). Portanto, "nenhum sistema de signo é dotado de mecanismo que lhe permita funcionar isoladamente" (IVÁNOV et al., 2003, p. 99) e "do ponto de vista semiótico, a cultura pode ser considerada como uma hierarquia de sistemas semióticos particulares" (Ibid., p. 119). Essas relações dão à cultura seu caráter dinâmico, sempre se renovando por conta da ação do signo, sendo constituída de formações semióticas que se encontram em diversos níveis, cujo funcionamento está condicionado à existência de um espaço semiótico da cultura.

Lotman (1996) apresenta o conceito de semiosfera a partir da analogia com o conceito de biosfera de Vernadski. Ao se referir às investigações semióticas no ato comunicacional, Lotman compreendeu que 
no existen por sí solos en forma aislada sistemas precisos y funcionalmente unívocos que funcionan realmente. [...] La separación de éstos [sistemas] está condicionada únicamente por una necesidad heurística. Tomado por separado, ninguno de ellos tiene, en realidad, capacidad de trabajar. Sólo funcionan estando sumergidos en uno continuum semiótico, completamente ocupado por formaciones semióticas de diversos tipos y que se hallan en diversos niveles de organización. A ese continuum, por analogía con el concepto de biosfera introducido por V. I. Vernadski, lo llamamos semiosfera. (LOTMAN, 1996, p. 22).

Quando introduz o conceito de semiosfera, Lotman aponta para a impossibilidade dos sistemas semióticos funcionarem de forma isolada. Os sistemas existentes nesse continuum só atuam se estiverem imersos nele. $\mathrm{O}$ autor se refere à incapacidade de os sistemas de signos atuarem fora desse espaço semiótico, alertando que o funcionamento desses sistemas de signos só é possível dentro da semiosfera, sendo essa a dinâmica dos sistemas semióticos da cultura no espaço da semiosfera.

Podemos compreender a semiosfera como um espaço semiótico de caráter abstrato (LOTMAN, 1996). Lotman diz que só dentro desse espaço é possível a realização da comunicação, entendida como processo. $\mathrm{O}$ autor diz que "sólo dentro de tal espacio resultan posibles la realización de los procesos comunicativos y la produción de nueva información" (Ibid., p. 23). Fora desse espaço semiótico, é impossível a existência da semiose, e a linguagem não só não funciona como também não pode existir. Esse caráter imprescindível do espaço semiótico da semiosfera indica que sua existência precede a linguagem, pois não só a semiosfera é necessária para a existência da linguagem como também permite a produção de nova informação. Isso significa que estudar os processos semióticos comunicativos implica em estudá-los imersos na semiosfera, nesse espaço constituído de formações semióticas diversas organizadas em vários níveis.

Desse modo, toma-se aqui a semiosfera como um espaço relacional por excelência, ou seja, um espaço onde processos comunicativos de sistemas diversos se encontram em constante atividade. Por isso, conhecer as relações entre os sistemas de signos existentes no espaço da semiosfera se faz necessário, uma vez que a semiosfera pode ser compreendida como um grande sistema da qual fazem parte as linguagens da cultura. Assim, entendemos o espaço formado pela obra, o artista e a cidade como um espaço semiótico formado por diversos sistemas de signos que desencadeiam distintos níveis de processos comunicativos, extrapolando, por vezes, o próprio limite desse espaço.

Para fins metodológicos, utilizamos o que Mesquita (2016) estabeleceu como categorias de análise em seu estudo (Figura 1). São elas:

1 Sistemas de base, formados pelos sistemas semióticos existentes no espaço externo da obra artística, sistemas esses que estabelecem processos encontrados na base da 
conformação do espaço pelo fato de manterem relações que possibilitam os processos com os sistemas intermediários e de superfície que se mantêm ocultos ao observador da obra;

2 Sistemas intermediários, formados pelos sistemas que estabelecem processos que funcionam intermediando os sistemas de base com os sistemas de superfície, ao mesmo tempo em que subsidiam a semiose destes; e

3 Sistemas de superfície, nos quais encontramos as linguagens visíveis a todos. Vemos aí os processos comunicativos que nos apresentam à primeira vista quando observamos a obra do artista.

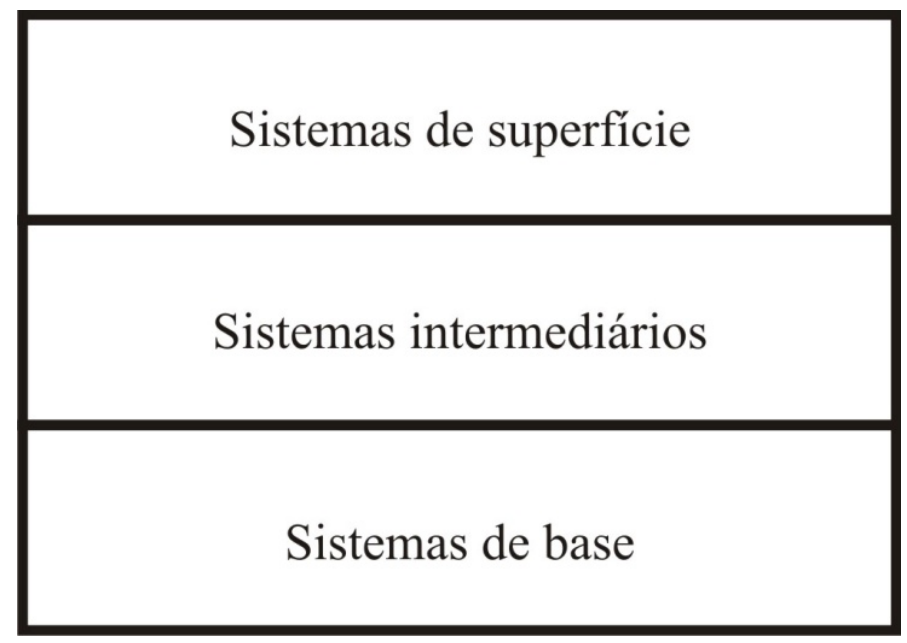

Figura 1. Sistemas de signos organizados em forma de camadas

Fonte: Mesquita (2016, p. 91)

Essas categorias identificadas por camadas de sistemas semióticos possibilitam três níveis de processos comunicativos: um primeiro nível existente entre os sistemas de base com os intermediários, um segundo nível entre os sistemas de base e os de superfície, e um terceiro existente entre os sistemas intermediários e os de superfície.

O método de análise usado por Mesquita seguiu um caminho que partiu dos processos comunicativos que são visíveis ao observador, iniciando a identificação a partir dos sistemas de superfície, passando pelos intermediários e, enfim, abordando os sistemas de base na constituição desse espaço semiótico da cultura. Desse modo, possibilitou, em primeira instância, conhecer como esses sistemas organizam os processos comunicativos, para em um segundo momento compreender como esses processos se formam a partir de sua origem.

Os sistemas de base desempenham um papel importante no processo comunicativo desses sistemas, uma vez que são eles que tornam possíveis os processos de semioses com os demais níveis do espaço semiótico, na medida em que subsidiam os processos 
comunicativos dos sistemas intermediários e de superfície. Isso significa que a semiose entre os sistemas de signos que compõem os sistemas de base produzem a informação necessária para os demais níveis comunicativos, estabelecendo assim, tal interdependência entre todos os sistemas de signos pertencentes a esse espaço semiótico.

Tanto os sistemas de base e os sistemas intermediários quanto os de superfície são considerados aqui sistemas de signos cuja principal função é servir de mediador entre as camadas de linguagens identificadas no espaço semiótico em análise. Essa mediação se dá por meio de processos comunicativos estabelecidos entre os sistemas encontrados. Isso quer dizer que os sistemas de base, os sistemas intermediários e os sistemas de superfície servem de elo entre os níveis estético, social, histórico, cultural, religioso etc. É por meio dos sistemas intermediários que os sistemas de superfície podem funcionar. Isso significa que os sistemas de signos da superfície desse espaço se encontram em níveis de interdependência com os sistemas intermediários, e que sem eles os sistemas de superfície não podem operar seus processos de semioses.

\section{Os procesos comunicativos nos desenhos de Moacir Andrade}

Coletamos 151 desenhos produzidos pelo artista durante as décadas de 1960 e 1970. Desses, selecionamos 50 desenhos para análise, buscando evitar os de temas e formas semelhantes. Objetivamos alcançar uma maior dinâmica ao escolher esses desenhos devido ao fato de serem de maior diversidade, excluindo os que não se relacionavam diretamente com o tema da cidade. Nos desenhos analisados, observamos modos de vida e de ocupar a cidade retratados sob o ponto de vista do artista. Podemos assim falar em modos de habitar a cidade, de trabalhar na cidade, de se mover na cidade, de cultuar na cidade, além do modo de ocupar a cidade e navegar o rio, e partindo dessas categorias de entendimento enxergamos os sistemas de signos em relação. São sistemas que indicam modos da vida social, econômica, religiosa, cultural e histórica, que se organizam em camadas, como vamos abordar mais adiante.

Em relação aos sistemas de superfície, o que é visível é a linguagem visual e formal do artista por meio de seu desenho, e a linha se apresenta como elemento principal da forma visual na produção do artista (Figura 2). Os desenhos de Moarcir Andrade apresentam características peculiares no que tange ao uso da linha na representação de seus temas. Desde os primeiros desenhos de sua infância até os mais atuais, seguem um estilo único com pouca ou quase nenhuma alteração. A grande preocupação do artista reside na comunicação do tema, que gira em torno da cultura amazônica - do folclore, dos tipos urbanos, da arquitetura da cidade e dos aspectos amazônicos em que o rio é o motivo.

$110 \frac{\text { Comunicação \& Inovação, PPGCOM/USCS }}{\text { v. 17, n. } 35 \text { (102-120) set-dez } 2016}$ 


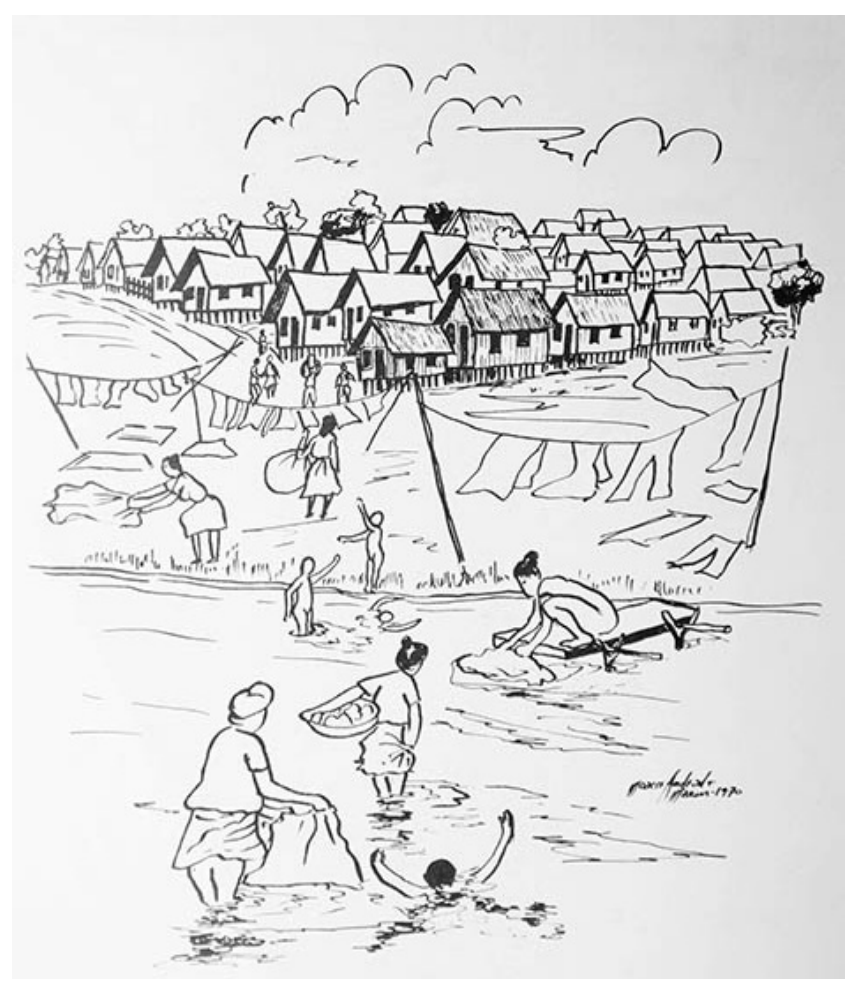

Figura 2. Lavadeiras do igarapé do 40, 1970

Fonte: Andrade (1982, p. 115)

Compõe essa camada a própria forma de expressão à qual o público tem acesso, o desenho. Compõem esse sistema a organização visual dos elementos da linguagem do desenho, o modo como esses elementos visuais estão relacionados na obra e o que se pode ver. Podemos também falar do modo como as linhas estão postas no papel, no caso do desenho: sua direção, a sobreposição, os cruzamentos, sua espessura, ou seja, a própria imagem visual.

Como vemos na Figura 2, a linha é o único recurso visual utilizado pelo artista para gerar suas representações. Nesse trabalho, o autor não se interessa em utilizar texturas para representar os detalhes da areia, do rio ou do céu. Há uma simplificação da forma. A linha livre e limpa é recorrente na organização visual do trabalho. Percebemos traços firmes e contínuos nas linhas dos quatro planos do desenho: o rio com as figuras das lavadeiras e crianças brincando, a areia com os varais, as casas de palafitas e ao fundo o céu, indicado apenas pelo uso de poucas linhas, assinalando um céu limpo e com poucas nuvens. Há a ausência de sombreamento. Apesar da simplicidade, o artista consegue ter êxito em sua representação das características de uma atividade econômica na cidade.

Em seus livros, o artista relata aspectos dessa prática. Assim, temos o conhecimento cultural do artista sobre o mundo a sua volta, e em particular a cidade de Manaus, na medida em que ele insere na obra traços distintivos desse espaço. Esses traços distintivos 
aparecem na obra de Moacir Andrade transformados por uma série de processos relacionais dinâmicos, e o que vemos na superfície dessa configuração semiótica é o resultado desses processos, a imagem do desenho.

Já na Figura 3, o artista dá ênfase aos detalhes visuais das fachadas da arquitetura na cidade de Manaus. O conjunto de casarões ao fundo nos apresenta características de uma construção do período áureo da borracha, na virada do século 19 para o 20 . O realismo da construção é acentuado pelo uso da perspectiva e se situa no plano visual central da composição. Diferente da Figura 2, o desenho da Figura 3 nos mostra o uso acentuado da textura, seja nas fachadas das contruções, seja nos telhados. A figura humana continua sendo representada de forma simplificada.

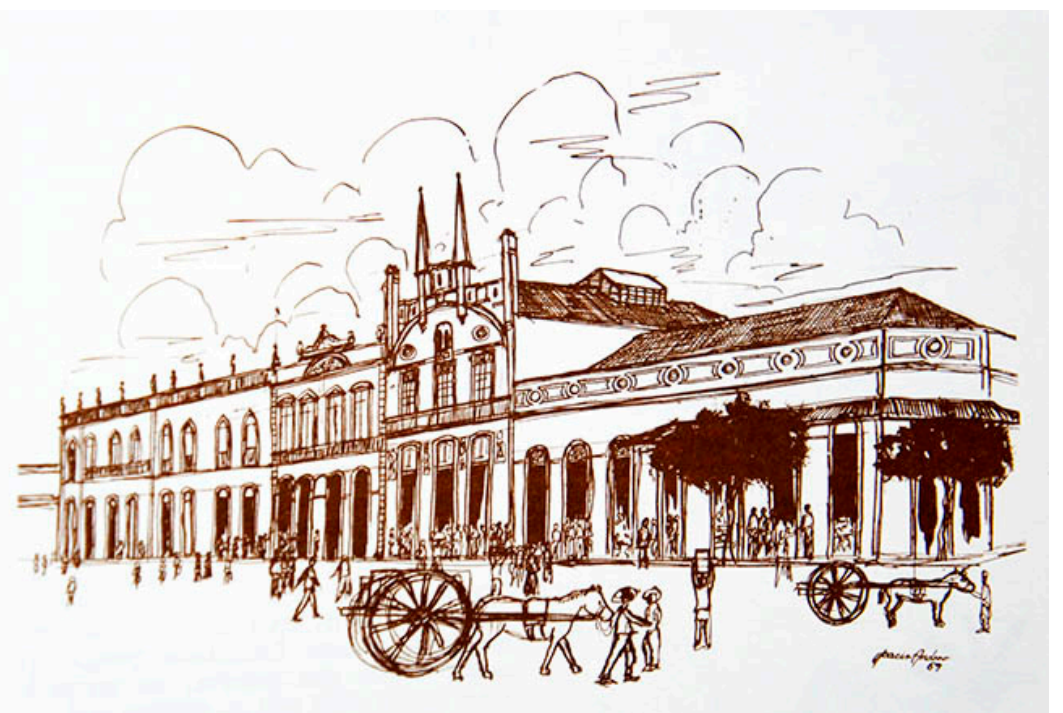

Figura 3. Sem título, 1969

Fonte: Andrade (1982, p, 47)

Já os sistemas intermediários são compostos pela linguagem pessoal do artista, sua estética, seu estilo. Nesse caso, podemos falar de um estilo individual e um estilo geral, seja de um povo ou de uma nação, além de um estilo de uma época, conforme enunciado por Wölfflin (2000). Chegamos nesse sistema a partir das características visuais identificadas na superfície, ou seja, nos traços distintivos da linguagem visual utilizada pelo artista. Por isso, mantém estreita relação com os sistemas de superfície. Os processos instaurados na superfície estabelecem características visuais que indicam o estilo artístico e a linguagem do artista.

Ao observar as Figuras 3 e 4, podemos notar um estilo misto que mescla dois modos de representação: o desenho técnico e o desenho à mão livre. O conhecimento do 
desenho técnico é fruto da formação do artista no curso de Marcenaria do Liceu Industrial de Manaus, atual Instituto Federal de Educação, Ciência e Tecnologia do Amazonas (IFAM), no período de 1942 a 1945, e de sua experiência como desenhista do escritório do engenheiro José Florêncio da Cunha Batista por quase 20 anos, na elaboração de projetos de construção civil.

Nas duas figuras, vemos um plano com um desenho de construções arquitetônicas, com o uso da técnica da perspectiva, e o desenho livre e simplificado (talvez primitivista) das figuras que compõem o primeiro plano da composição. Moacir Andrade iniciou sua prática de desenho livre a partir dos seus cinco anos de idade (um ano antes de se mudar para Manaus), quando morava com a família no interior do Amazonas, no sítio Nova Esperança, no município de Manacapuru.

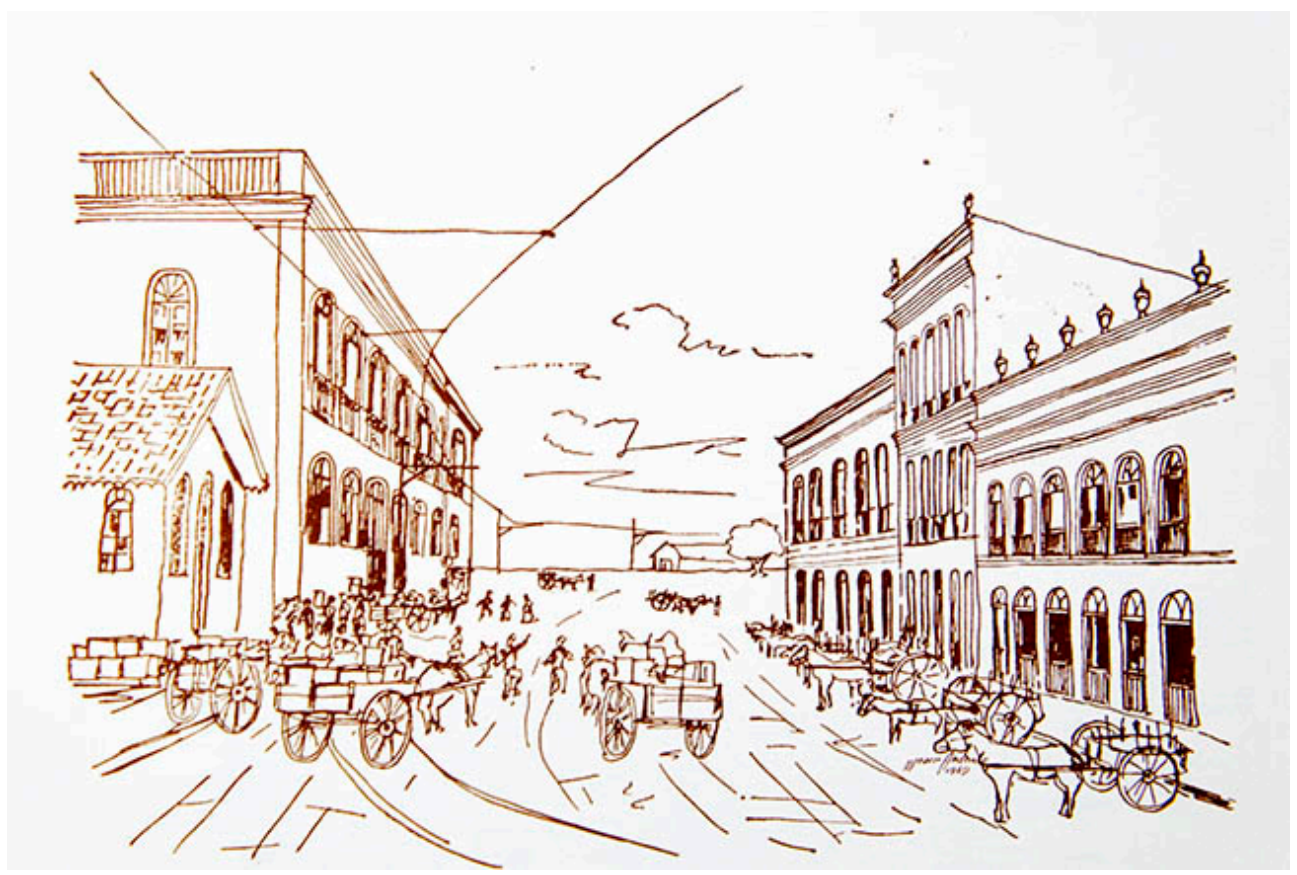

Figura 4. Sem título, 1969

Fonte: Andrade (1982, p. 51)

Os desenhos da infância do artista tinham um traço mais marcado e carregado, que somado à maneira de representação das formas formavam o seu estilo que se manteve com poucas alterações. A simplificação da forma humana é típica do trabalho de Moacir Andrade, e o detalhamento da representação da arquitetura da cidade se inicia depois da década de 1940. 
A partir dessa identificação, caminhamos para o primeiro nível dos sistemas, que é responsável pelos processos que se encontram na base dessa configuração semiótica. Assim, os sistemas de base são observados a partir daquilo que não está aparente, ao mesmo tempo que mantém relação com os processos da superfície, ou seja, da imagem. Nessa camada, encontramos o conteúdo que se realiza no espaço externo da obra, conformando o universo temático dos desenhos, formado pelos modos de vida da cidade, os costumes, os hábitos, as atividades econômicas, a vida religiosa etc.

A descrição dos processos comunicativos dos sistemas de base nos permitem compreender a dinâmica da cidade a partir do conhecimento dos temas representados nos desenhos. Esses processos descrevem o modo de habitar, de trabalhar, de se mover, de se manifestar e ocupar a cidade.

A representação da Figura 2, descrita anteriormente, apresenta traços distintivos do modo de vida de uma ação social, e também econômica, das lavadeiras à margem do igarapé do 40. Nesse desenho, podemos compreender e tomar conhecimento de uma das características que marcam uma manifestação cultural na cidade de Manaus, pois o título da obra indica uma atividade social e econômica e também o espaço e o tempo que marcam a história da cidade, ou seja, o igarapé do 40 e o ano de 1970.

Moacir Andrade descreve a atividade das lavadeiras do igarapé do 40 em seu livro Manaus: ruas, fachadas e varandas, de 1985. Percebemos um escritor que andava pelas ruas, observando, entrevistando, anotando e desenhando as cenas que via.

Alí, sentadas em pequenos jiraus já construídos, as lavadeiras exercitavam o seu "metier", lavando as roupas de seus fregueses ricos que pagavam 500 réis por peça de linho HJ lavado e engomado; cada lavadeira possuía o seu jirau à margem do igarapé.Muitas lavadeiras lavavam para diversas famílias constituídas de 3, 5, 8 membros, ganhando salários mensais. (ANDRADE, 1985, p. 191).

Nesse trecho, o autor nos dá um riquíssimo cenário histórico da organização do trabalho das lavadeiras às margens do igarapé do 40 , das relações econômicas, do consumo de roupas com o tecido de linho da marca HJ (ou S 120, como ele cita no mesmo livro), em atividade na cidade naquela época. E, ainda no livro de Moacir, o autor nos dá outras informações, como horário, marcas de barras de sabão (borboleta e tuxaua) e tecnologia, como o ferro de engomar a carvão. O autor chega a descrever todo o processo e técnica de engomar realizado pelas lavadeiras.

Nessa época, esse tipo de atividade era comum, como sugerem vários outros desenhos do artista. Além de uma cena de uma atividade na cidade de Manaus, temos ainda um traço marcante do modo de vida na cidade, as casas em palafitas à beira do rio e o próprio rio. 
Torna-se interessante, também, o ponto de vista do artista. Ele mostra nesse desenho a cidade ao fundo, o que nos faz pressupor que o pintor se deslocava até o rio, possivelmente de canoa, como o próprio artista chegou a relatar em uma de suas muitas biografias.

As Figuras 5 e 6 mostram características do modo de habitar do homem na cidade de Manaus nas décadas de 1960 e 1970. O artista, ao caminhar pelas ruas da cidade e navegar pelos rios e igarapés, apreende uma aura (no sentido em que Walter Benjamin deu ao termo) por meio de uma representação artística.

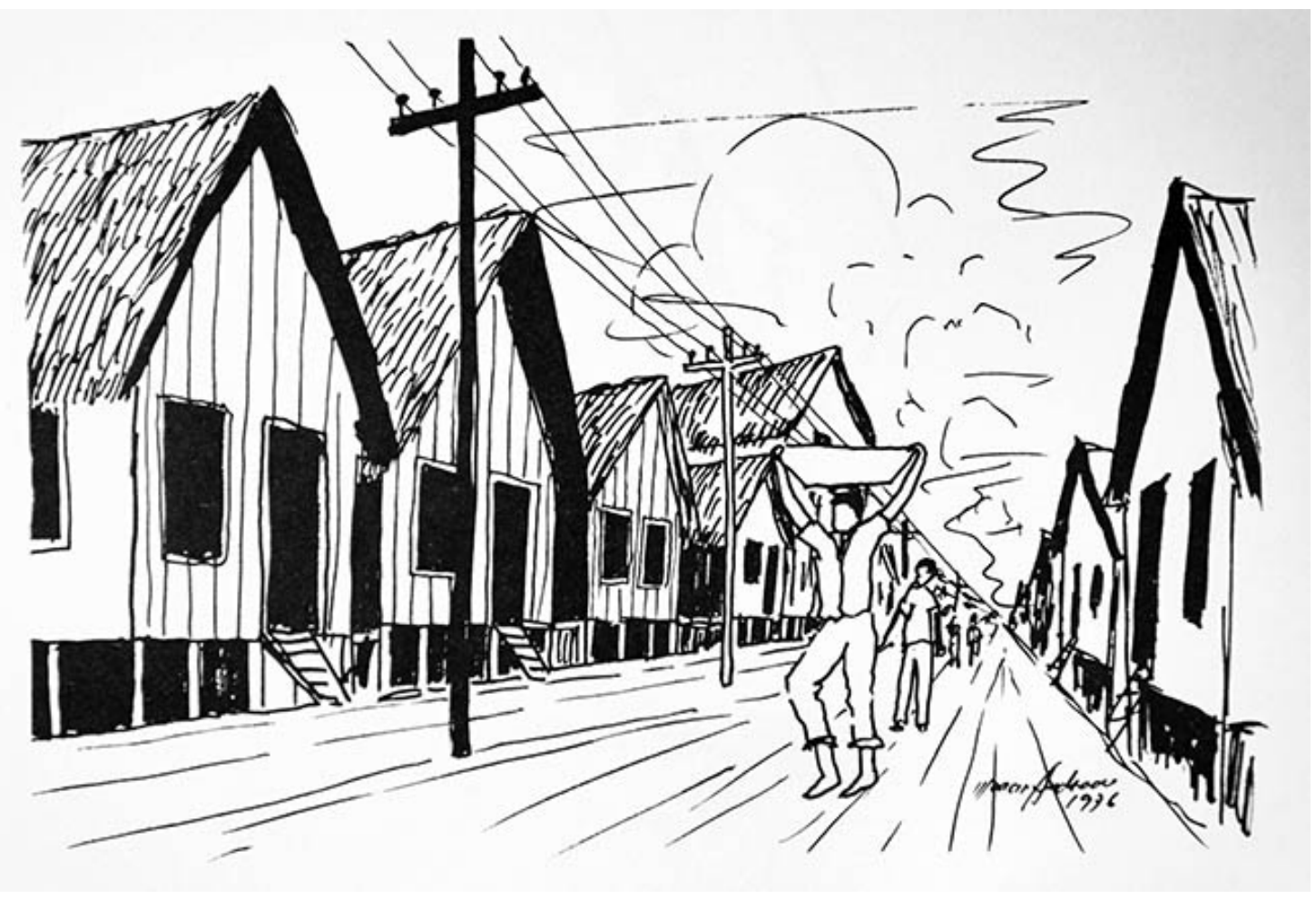

Figura 5. Sem título, 1976

Fonte: Andrade (1982, p. 86)

É peculiar a relação da cidade com o rio. Moacir retrata diversos cenários de Manaus junto do rio, por exemplo, o modo como se configuram as casas de palafitas às margens dos igarapés. Na Figura 6, essa vista é possível somente a partir da década de 1960, quando se constroem as duas pontes da Avenida Sete de Setembro (OLIVEIRA, 2003), sendo a segunda ponte o ponto no qual o artista se situa para observar a paisagem e estudar o espaço. Isso significa dizer que sem a construção da ponte, o ponto de vista seria diferente, e a cena representada mudaria suas formas. 


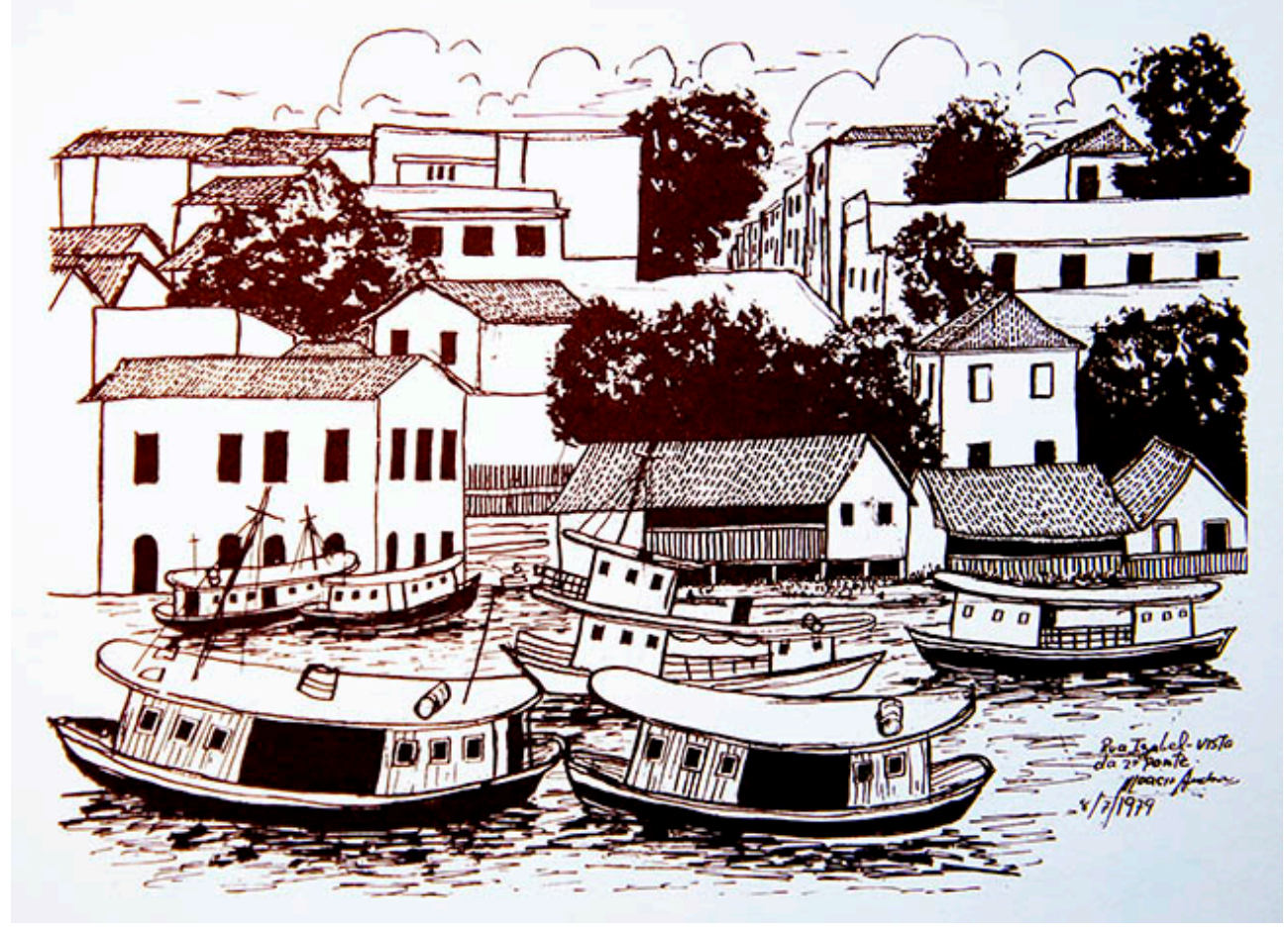

Figura 6. Rua Izabel - vista da segunda ponte, 1979

Fonte: Andrade (1982, p. 59)

A paisagem urbana da área da Rua Isabel, no centro da cidade, à margem do igarapé de Manaus, se modificou substancialmente na atualidade. Temos então um desenho do artista de caráter histórico, uma vez que desapareceu a dinâmica dos barcos e canoas que navegavam nessa área e as fachadas das casas se alteraram, além de desaparecerem algumas residências. Do mesmo modo, a relação do artista com a pasaigem apreendida, retratada a partir do ponto de vista da segunda ponte da Avenida Sete de Setembro, se encontra em constante transformação: primeiro que essa ponte foi construída na década de 1960; segundo que atualmente que esse igarapé se encontra aterrado - obra realizada pelo Programa Ambiental e Social dos Igarapés de Manaus (Prosamin), iniciado em 2003 pelo governo do estado do Amazonas.

$\mathrm{Na}$ área do igarapé de Manaus representada na Figura 6 se encontra o Parque Jefferson Péres, sendo que parte do igarapé que cruza o parque foi canalizada e outra parte foi aterrada e uma área residencial tomou seu lugar, o Parque Residencial Manaus.

Outro tema recorrente nos desenhos de Moacir Andrade são os vendedores ambulantes. Como o artista, esses vendedores (Figura 7) são retratados caminhando pela cidade numa dinâmica urbana típica. Essa prática era tão comum na década de 1970 que o artista registrou cerca de vinte desenhos representando vendedores ambulantes. 


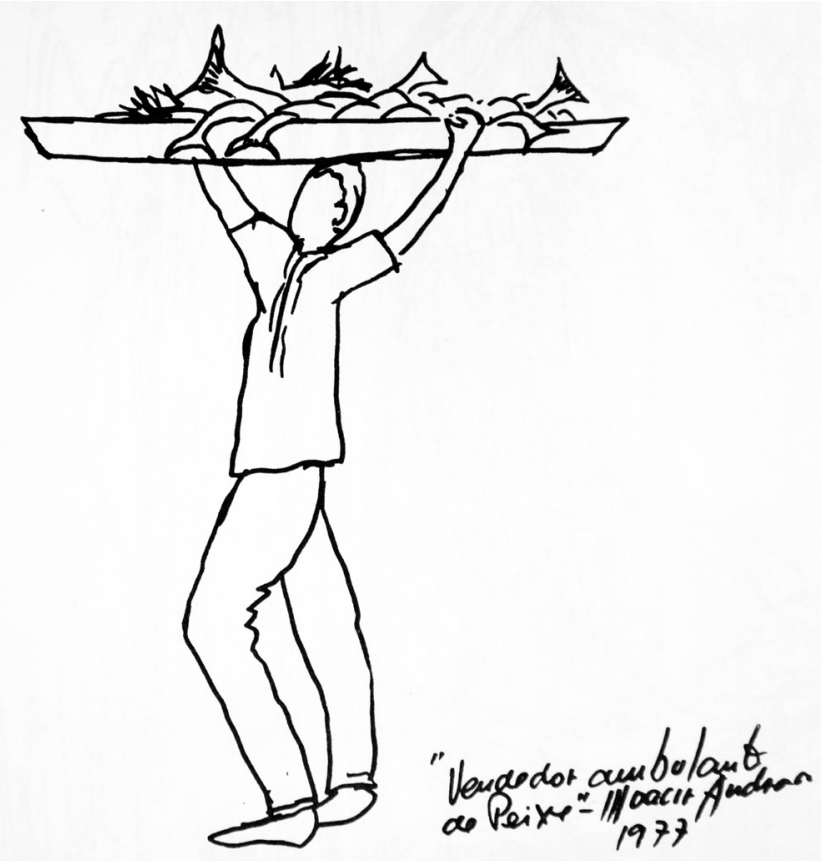

Figura 7. Vendedor ambulante de peixe, 1977

Fonte: Andrade (1978, p. 198)

Vemos que o artista Moacir Andrade caminhava pelas ruas da Zona Central de Manaus e buscava representar a dinâmica urbana da cidade, no seu vai e vem dos transeuntes (rastros), das carroças e da paisagem arquitetônica que se modifica com o tempo.

Ao representar a cidade, Moacir Andrade transforma as relações sociais dos distintos tipos que vendem peixe, palha, gelo etc. nas ruas da cidade em formas simbólicas, em desenhos. É desse modo que devemos pensar a obra do artista e sua relação com a cidade, tomando-a como resultado de diversos diálogos estabelecidos entre o artista e o espaço urbano.

Podemos, então, buscar responder de que modo a arte se relaciona com o urbano, identificando as formas expressivas criadas pelo artista, propondo uma metodologia de análise de processos culturais em uma obra de arte.

A partir dessa compreensão, é possível estabelecer tessituras acerca dos sistemas envolvidos nesse processo de representação, e assim, se aproximar de sua estrutura, partindo da hipótese de que, como a cultura é dinâmica, todo processo cultural na arte se dá na ação estabelecida nas relações entre os diversos sistemas simbólicos que fazem parte da cultura por meio de representações.

Em todo processo de criação, o artista dialoga com o mundo, consigo, com os materiais e com a própria obra em construção (SALLES, 2007). Essas relações se apresentam mais complexas do que aparentam. No entanto, esse diálogo não termina com a obra - existe a relação da obra com o espaço e com o espectador, e do artista com os sistemas culturais. 
Toda obra de arte desencadeia um processo cultural que ultrapassa o seu universo. A compreensão de mundo, do tempo e espaço faz parte desse processo, porque vemos na obra uma história. A partir da obra, pode-se chegar à construção de sua história, determinar o tempo em que ela foi elaborada e seu lugar de produção, além dos processos culturais que são instaurados por ela.

Toda obra de arte se encontra imersa em linguagens. Em relação à obra de Moacir Andrade, vemos que seus desenhos se encontram na esfera da linguagem visual. Nela é possível perceber uma linguagem particular, pois o artista opta por trabalhar com um estilo mais livre, mais particular, sem estar preso a cânones estilísticos.

Temos o conhecimento cultural do artista sobre o urbano na cidade de Manaus na medida em que ele insere na obra traços distintivos dessas manifestações. Esses traços distintivos aparecem na obra de Moacir Andrade transformados por uma série de processos relacionais dinâmicos.

Ao transformar o conteúdo dessas manifestações, o artista se apropria de linguagens artísticas, como o desenho. Por meio do desenho, Moacir Andrade expande seu universo criativo tomando o conteúdo do urbano na Amazônia, instaurando um universo novo da cultura, em que espontaneidade, liberdade e subjetividade se encontram na criação de sua obra. De posse dessas inferências, é possível conhecer a visão do urbano amazônico, desde o ponto de vista do artista até a forma como ele interpreta e representa esse universo, além de compreender o próprio artista como ser atuante nesse ambiente; assim, torna-se possível realizar um estudo da cultura, dos modos de vida e tipos urbanos da cidade por meio da descrição e análise das representações artísticas.

Desse modo, podemos falar de processos culturais totais, que abarcam toda a esfera do cultural (religioso, histórico, econômico, social, estéticos, entre outros). Essa categoria nasce da necessidade de se estudar a temática, que é plural, na obra de Moacir Andrade, buscando uma aproximação com a ideia de que o universo de categorias tratadas na obra do artista forma um conjunto estruturado de sistemas.

Vale dizer que os processos culturais se estruturam em camadas, que necessariamente se articulam de forma oculta na obra do artista. O que é visível ao observador é a linguagem visual (o desenho). Tomamos a representação dos processos culturais na obra de Moacir Andrade conforme a Figura 8, na qual representamos a camada "desenho", acima da linha pontilhada, pois são as imagens vísiveis ao observador; as demais se situam abaixo dessa linha, ficando ocultas e necessitando de análise. Essa representação que apresentamos na Figura 8 é fruto da analogia à imagem do iceberg, em que uma pequena parte do bloco de gelo é vísivel na superfície, enquanto uma grande massa, que sustenta a camada visível, se mantém oculta da superfície. 


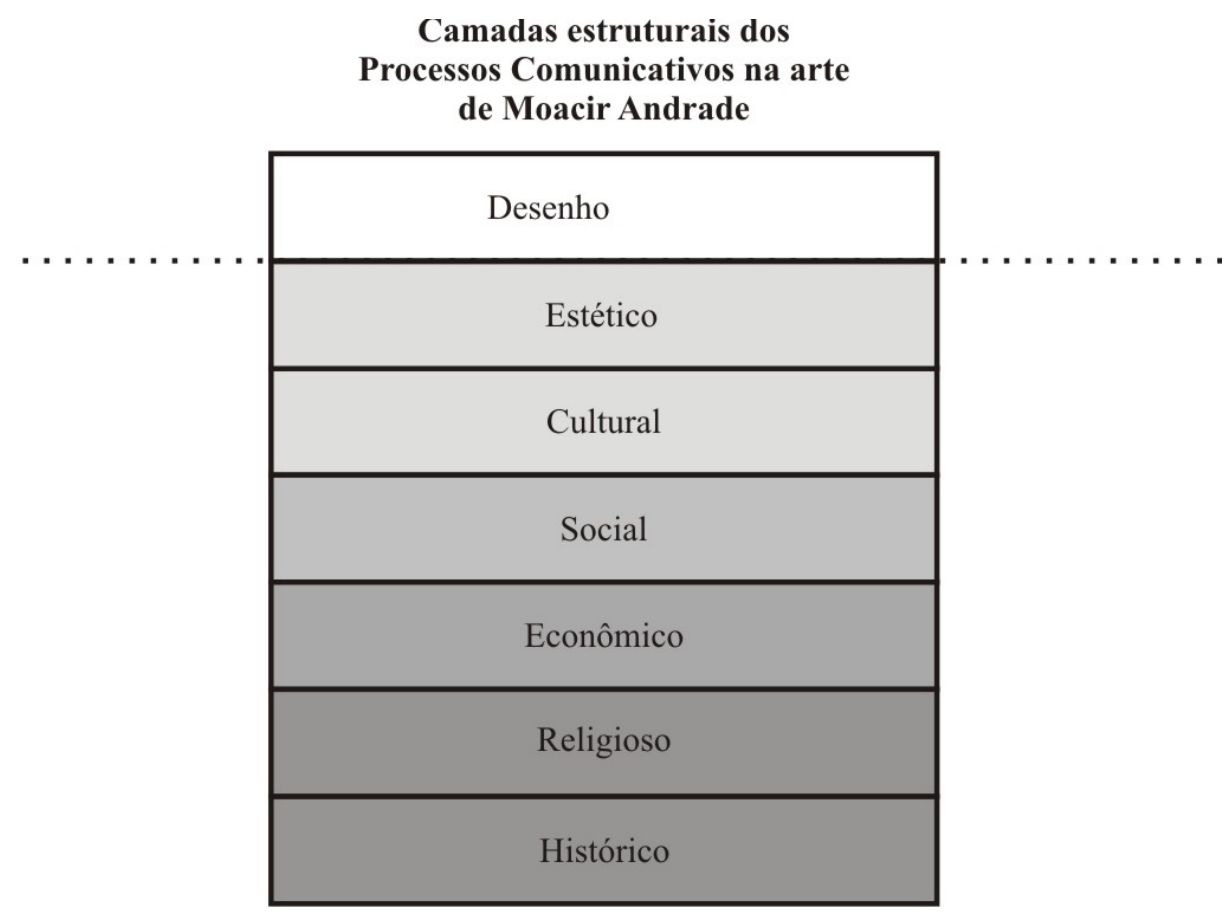

Figura 8. Representação da estrutura dos processos culturais

Fonte: Mesquita (2016)

Essa representação em camadas decorre da ideia de se observar os vários sistemas existentes nos processos comunicativos na obra de Moacir Andrade. Essa visão se assemelha a várias folhas transparentes de acetato, sobrepostas uma a uma. Imaginemos que cada folha representa uma camada e que sua transparência nos permite vislumbrar parte do conteúdo da camada inferior, chegando a um ponto que a última camada, situada na base dessa configuração, se torna mais ofuscada, dificultando a identificação total do conteúdo pertencente à ela. O desafio resulta do modo como estão organizadas essas filas de camadas, cabendo tal tarefa ao pesquisador. O papel de cada camada, semelhantemente às categorias de análise de Mesquita (2016), é possibilitar os processos comunicativos entre as camadas superior e inferior dessa estrutura.

\section{Referências}

ANDRADE, M. Catálogo. Manaus: Imprensa Oficial, 1974. . Alguns aspectos da antropologia cultural do Amazonas. Manaus: Casa Editora Madrugada, 1978. Manaus: monumentos, hábitos e costumes. Manaus: Humberto Calderado, 1982. Manaus: ruas, fachadas e varandas. Manaus: Humberto Calderado, 1985. 
IVÁNOV, V. V. et al. Teses para uma análise semiótica da cultura (uma aplicação aos textos eslavos). In: MACHADO, I. Escola de semiótica: a experiência de Tártu-Moscou para o estudo da cultura. Cotia: Ateliê, 2003. p. 99-132.

LOTMAN, I. M. La semiosfera I: semiótica de la cultura y del texto. Selección e traducción del russo Desiderio Navarro. Madrid: Frónesis Cátedra Universitat de València, 1996.

. La semiosfera II: semiótica de la cultura, del texto, de la conducta y del espacio. Selección e traducción del russo Desiderio Navarro. Madrid: Frónesis Cátedra Universitat de València, 1998. Sobre o problema da tipologia da cultura. Tradução Lucy Seki. In: SCHNAIDERMAN, B.; SEKI, L. (Orgs.). Semiótica russa. Tradução Aurora Fornoni Bernardini. 2. ed. São Paulo: Perspectiva, 2010. p. 31-41.

MACHADO, I. O ponto de vista semiótico. In: HOHLFELDT, A.; MARTINO, L. C.; FRANÇA, V. V. (Orgs.). Teorias da comunicação: conceitos, escolas e tendências. 3. ed. Petrópolis: Vozes, 2003.

MESQUITA, V. Semioses na web: os processos comunicativos do Google art project. Curitiba: Appris, 2016.

MONTE-MÓR, R. L. O que é o urbano, no mundo contemporâneo. In: Revista Paranaense de Desenvolvimento, Curitiba, n. 111, p. 9-18, 2006. Disponível em: <http://www.ipardes.pr.gov.br/ ojs/index.php/revistaparanaense/article/view/58/61>. Acesso em: 8 ago. 2016.

OLIVEIRA, J. A . Cidades na selva. Manaus: Valer, 2000. Manaus de 1920-1967: a cidade doce e dura em excesso. Manaus: Valer, EDUA, 2003.

PÁSCOA, L. As artes plásticas no Amazonas: o clube da madrugada. Manaus: Valer, 2011.

PEIRCE, C. S. (1931). Collected papers of Charles Sanders Peirce. In: HARTSHORNE C., WEISS P. (Orgs.). . Cambridge, MA: Harvard University Press, 1994. v. I-VI; PEIRCE, C. S. (1958). Collected papers of Charles Sanders Peirce. In: BURKS, A. (Ed.). Cambridge, MA: Harvard University Press, 1994. v. VII-VIII.

PINACOTECA DO ESTADO. Disponível em: <http://www.cultura.am.gov.br/pinacoteca-do-estado/>. Acesso em: 16 jul. 2014.

SALLES, C. A. Gesto inacabado: processo de criação artística. 3. ed. São Paulo: Annablume, 2007.

SOUZA, E. Moacyr de todas as cores. Manaus: Muiraquitã, 2010.

WIRTH, L. O urbanismo como modo de vida. In: VELHO, O. G. (Org.). O fenômeno urbano. Rio de Janeiro: Zahar, 1967. p. 97-112.

WÖLFFLIN, H. Conceitos fundamentais da história da arte: o problema da evolução dos estilos na arte recente. Tradução João Azenha Júnior. 4. ed. São Paulo: Martins Fontes, 2000. 